\title{
Nitrogen regime of haplic Luvisol in orchards at fertilization
}

\author{
Elena Leonicheva, Tatyana Roeva, Larisa Leonteva*, and Maxim Stolyarov \\ Russian Research Institute of Fruit Crop Breeding (VNIISPK), Zhilina, Orel district, Orel region, \\ Russian Federation
}

\begin{abstract}
The aim of the investigation was to research the mineral nitrogen $(\mathrm{N}$ min $)$ behavior in loamy haplic Luvisols of orchards located in the forest-steppe zone of the Central Russian Upland. The seasonal dynamics of $\mathrm{N}$ min (ammonium + nitrates) was studied during the growing seasons of 2018 and 2019 in field experiments with apple and sour cherry. Fertilizers were applied annually in spring at doses increasing from $\mathrm{N} 30 \mathrm{~K} 40$ to N120K160. The most important factors influencing the nitrogen dynamics were meteorological conditions, productivity of trees, peculiarities of nitrogen uptake by the studied crops. Fertilization of orchards with nitrogen contributed to an increase in $\mathrm{N}$ min content by $1.5 \ldots$ 5 times, depending on the dose. The dynamics of $\mathrm{N}_{\min }$ in the soil of fertilized and unfertilized plots was similar and depended on the biological features of the crops: the lowest indicator's level in the soil under sour cherry was in July during fruit ripening, while in the apple orchard a low nitrogen content was noted in August. Studies have shown that in the climatic conditions of the Central Russian Uplands, loamy haplic Luvisols without additional application of nitrogen fertilizers can provide a favorable level of nitrogen nutrition for apple and sour cherry trees in the first years of fruiting.
\end{abstract}

\section{Introduction}

The ecologically-friendly management of plants' mineral nutrition in agroecosystems is an actual problem of contemporary agriculture. Optimization of nitrogen nutrition is one of the most significant aspects of this problem, which is associated with the important role of nitrogen in key biochemical processes of living organisms and with the complexity of this element's biogeochemical cycle in the atmosphere-soil-plant system [1, 2]. The management of nitrogen nutrition is complicated in agroecosystems with perennial plants such as fruit trees since they are characterized by the uptake of nutrients not only for fruiting, but also for the continuous growth and development of vegetative organs, as well as a well-developed ability to store elements and to re-utilize it later [3].

\footnotetext{
* Corresponding author: agro@vniispk.ru
} 
For fruit trees, especially in the first years after planting, the nitrogen utilization rate is quite low and amounts to $15 \ldots 33 \%$ [4,5]. For this reason, some fruit growers believe they should apply an amount of nitrogen much higher than the remove of the element with the crop [3]. On the other hand, since fruit crops distribute a significant part of assimilates into fruits that have a low content of nitrogenous compounds, trees do not need to continuously uptake large amounts of nitrogen from the soil. The economical use of nitrogen by trees in perennial plantations makes it possible to create fertilization systems for orchards that ensure sustainable productivity while safety of environmental requirements.

The elaboration of precision nutritional management for different crops is possible only on the basis of detailed information regarding the peculiarities of the nutrients' "behavior" in specific soil and climatic conditions during the cultivation of specific crops. In this respect, orchard agrocenoses have been studied much less than agroecosystems with annual plants.

The purpose of this study was to research the nitrogen regime of loamy haplic Luvisol under plantations of pome (apple) and stone (sour cherry) fruit crops in connection with the meteorological conditions of the growing season, the fruit load of trees and the use of mineral fertilizers.

\section{Materials and methods}

The studies were carried out in 2018-2019 in medium-sized apple (planted in 2013) and cherry (planted in 2015) orchards located in the orchard area of the Russian Research Institute of Fruit Crop Breeding (Oryol Region). The apple trees allocation scheme was $6 \mathrm{x}$ $3 \mathrm{~m}$, cherry trees $-5 \times 3 \mathrm{~m}$. The following varieties were selected for research: apple trees 'Ven'yaminovskoe' on a semi-dwarf rootstock 54-118, cherry - 'Turgenevka' on a rootstock V-2-180.

The soil of the experimental plots was loamy haplic Luvisol underlain by dolomite limestones. Agrochemical parameters of soil in the $0 \ldots 20 \mathrm{~cm}$ layer are presented in Table 1. During the experiment, the soil in the rows of trees was treated with herbicides, while in the aisles the grass was mowed.

Table 1. Soils characteristics of trial orchards.

\begin{tabular}{|l|c|c|c|c|c|}
\hline Fruit crops & \multirow{2}{*}{$\mathrm{pH}_{\mathrm{KCl}}$} & Organic matter (\%) & $\mathrm{N}_{\mathrm{ag} .}$ & $\mathrm{P}_{2} \mathrm{O}_{5}$ & $\mathrm{~K}_{2} \mathrm{O}$ \\
\cline { 4 - 6 } & & & \multicolumn{3}{|c|}{$\mathrm{mg} / \mathrm{kg}$} \\
\hline Apple tree & 5.39 & 2.67 & 99.07 & 146.22 & 78.24 \\
\hline Sour cherry & 5.80 & 2.78 & 108.45 & 383.16 & 120.18 \\
\hline
\end{tabular}

The soil of both experimental orchards is characterized by a high content of available phosphorus. At the same time, the soil of the apple orchard has a low level of alkalihydrolysable nitrogen and exchange potassium, and the soil of the cherry orchard has a medium level as per the gradation of soils by the supply of mineral nutrients, which elaborated for fruit crops [6,7]. Such features of the soil agrochemical parameters determined the choice of nitrogen and potassium fertilizers for experiments to optimize the mineral nutrition of the studied crops.

The application of fertilizers in apple orchard started in 2015, and in sour cherry orchard - in 2017. Fertilizers were applied annually in spring to a depth of $10-15 \mathrm{~cm}$. In the experiment with apple trees, nitrogen and potassium were used in the form of granular $\mathrm{NH}_{4} \mathrm{NO}_{3}$ and $\mathrm{KCl}$ according to the following scheme: 1. Control (without fertilizers); 2 . $\mathrm{N} 30 \mathrm{~K} 40 ; 3$. N60K80; 4. N90K120. In the experiment with sour cherry, granular $\left(\mathrm{NH}_{2}\right)_{2} \mathrm{CO}$ and $\mathrm{K}_{2} \mathrm{SO}_{4}$ were applied, and the fertilizer doses were as follows: 1. Control; 2. N30K40; 3. N60K80; 4. N90K120; 5. N120K160. 
The experiments were carried out in four repetitions, there are 5 trees on each record plot.

During two growing periods, soil samples were taken monthly from May to September, in which the content of $\mathrm{N}_{\min }$ was determined. Sampling was carried out in the undercrown tree zone at a distance of $1.0 \ldots 1.5 \mathrm{~m}$ from the trunk from a depth of $0 \ldots 20 \mathrm{~cm}$. In fresh soil samples after delivery to the laboratory, the content of ammonium and nitrates was determined immediatly.

The content of nitrate nitrogen in the soil was determined potentiometrically in a suspension of $1 \%$ potassium alum solution at a soil:solution ratio of 1:2.5 using an IT-1201 nitrate meter. Ammonium nitrogen was extracted from the soil with a $0.05 \mathrm{M} \mathrm{NaCl}$ solution at a soil:solution ratio of 1:30. The ammonium content in the extract was determined photometrically with Nessler's reagent on a SmartSpect ${ }^{\mathrm{TM}}$ Plus spectrophotometer [8]. The total amount of mineral nitrogen was calculated as the sum of nitrogen in the ammonium and nitrate forms.

Samples of apple and sour cherry leaves were taken in the last decade of July from the middle part of annual shoots. Sample processing and preparation were carried out in accordance with standard laboratory procedures $[8,9]$. The nitrogen content in the leaves was determined by the Kjeldahl method [8] using VILITEK equipment (Vilitek LLC (Moscow, Russia).

Yield accounting was carried out by the weight method considering the weight of fruits from each experimental tree [9].

For statistical data processing, one-way and two-way analysis of variance were used with an assessment of differences significance based on the Fisher's criterion and LSD at a significance level of $\mathrm{P}=0.05[10]$.

\section{Results and discussion}

For apple orchards grown in the climatic conditions of the Central Russian Upland, a significant effect of meteorological conditions and tree productivity on the level of mineral forms of nitrogen in the soil has been shown $[11,12]$. The same factors have a significant impact on the $\mathrm{N}_{\min }$ dynamics in the soil of young sour cherry orchards entering fruiting [13, 14].

During the research, the studied orchards were just entering the fruiting period. The first marketable crop of apple was obtained in 2017, cherry - in 2018. In average, for all variants of the experiment, productivity of sour cherry trees was at the level of $4.61 \pm 0.54 \mathrm{~kg} / \mathrm{tree}$ in 2018 and $8.24 \pm 0.74 \mathrm{~kg} /$ tree in 2019, for the apple trees these indicators were $28.00 \pm 2$, 20 and $5.99 \pm 1.11 \mathrm{~kg} /$ tree, respectively. The effect of nitrogen and potash fertilizers on the productivity of both crops was statistically insignificant (Table 2), which is consistent with the literary data on the weak effect of mineral fertilizers on the productivity of apple and cherry in the first years of fruiting $[7,15,16]$.

Table 2. Productivity of sour cherry trees cv. 'Turgenevka' and apple trees cv. 'Ven'yaminovskoe', 2018-2019 (kg/tree).

\begin{tabular}{|l|c|c|c|c|}
\hline \multirow{2}{*}{ Treatments } & \multicolumn{2}{|c|}{ Sour cherry cv. 'Turgenevka' } & \multicolumn{2}{c|}{ Apple tree cv. 'Ven'yaminovskoe' } \\
\cline { 2 - 5 } & 2018 & 2019 & 2018 & 2019 \\
\hline Control (no fertilizer) & 4.38 & 8.24 & 27.39 & 5.86 \\
\hline N30K40 & 4.26 & 8.46 & 28.11 & 5.49 \\
\hline N60K80 & 3.90 & 8.67 & 31.37 & 6.02 \\
\hline N90K120 & 5.12 & 7.01 & 28.06 & 6.04 \\
\hline N120K160 & 5.38 & 9.33 & - & - \\
\hline LSD 0.05 & NS & NS & NS & NS \\
\hline
\end{tabular}


Characteristics of hydrothermal conditions in the period from May to September 2018 and 2019 is presented in Figure 1. In 2018, the monthly temperature exceeded the average annual indices by $1 \ldots 3{ }^{\circ} \mathrm{C}$. In 2019 , the temperature regime was closer to the long-term average values, however, May and June were also characterized by higher temperatures. A feature of the growing season in 2018 was contrasting moisture conditions: drought was observed from late May to mid-July and in August, while $119 \mathrm{~mm}$ of precipitation fell from 13 to 25 July. In 2019, the dry period lasted from late May to the third decade of June; precipitation was more uniform in the following months.

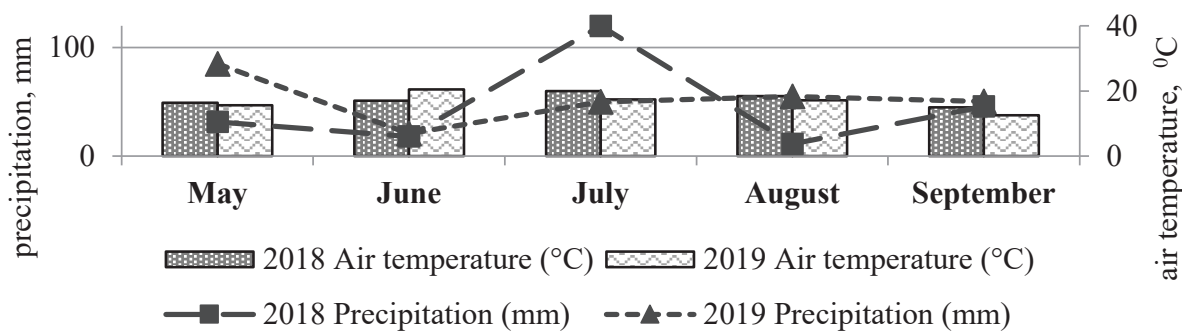

Fig. 1. Monthly and growing season precipitation and temperature in 2018 and 2019.

The third significant factor that influenced the dynamics of $\mathrm{N}_{\min }$ in the soil of the studied orchards were the features of nitrogen uptake by the studied crops. Fruit trees have the highest nitrogen demand during the period of intensive growth and fruit ripening. Cherry trees have a shorter period from flowering to fruit ripening compared to apple trees. The fruits of the studied variety 'Turgenevka' ripen in the first ten days of July; in both years. In average, for all variants of the experiment, the $\mathrm{N}_{\min }$ content in the soil of the sour cherry orchard significantly decreased in July compared with the June value of the indicator (Table 3 ). In 2018, the July level of mineral nitrogen was $3 \ldots 5$ times lower than in the previous month, and in 2019 the values of the indicator in July were $1.2 \ldots 1.5$ times lower than the June values, depending on the variant of the experiment. The sharp decrease in the content of $\mathrm{N}_{\text {min }}$ in July 2018 may also be associated with leaching of studied compounds' by intense rain fall in the period from July 13 to 25 .

Table 3. Seasonal dynamics of $\mathrm{N}_{\min }\left(\Sigma\left(\mathrm{N}-\mathrm{NH}_{4}+\mathrm{N}-\mathrm{NO}_{3}\right)\right.$ in the soil of apple and sour cherry orchards, 2018-2019 (mg/kg)

\begin{tabular}{|c|c|c|c|c|c|c|c|}
\hline \multirow[t]{2}{*}{ Fruit crops } & \multirow[t]{2}{*}{ Factor A (treatments) } & \multicolumn{5}{|c|}{ Factor B (sampling time) } & \multirow[t]{2}{*}{ Mean A } \\
\hline & & May & June & July & August & September & \\
\hline \multirow[t]{16}{*}{ Sour cherry } & \multicolumn{7}{|c|}{2018} \\
\hline & Control (no fertilizer) & 29.9 & 18.2 & 5.7 & 5.9 & 16.7 & 15.3 \\
\hline & $\mathrm{N} 30 \mathrm{~K} 40$ & 33.2 & 45.9 & 5.7 & 8.3 & 15.5 & 21.7 \\
\hline & N60K80 & 50.7 & 54.0 & 10.8 & 11.8 & 18.6 & 29.2 \\
\hline & N90K 120 & $119.5^{*}$ & 40.4 & 8.0 & 8.8 & 20.9 & 35.7 \\
\hline & N120K160 & $147.6^{*}$ & $99.8^{*}$ & 25.5 & 40.2 & 33.7 & $69.4^{*}$ \\
\hline & Mean B & 76.2 & 51.7 & 11.2 & 14.9 & 21.1 & \\
\hline & \multicolumn{4}{|c|}{$\mathrm{LSD}_{05} \mathrm{~A}=26.8$} & \multicolumn{2}{|c|}{$\mathrm{LSD}_{05} \mathrm{~A} \times \mathrm{B}=60.1$} & \\
\hline & \multicolumn{7}{|c|}{2019} \\
\hline & Control (no fertilizer) & 20.3 & 31.7 & 20.0 & 17.3 & 22.9 & 22.4 \\
\hline & $\mathrm{N} 30 \mathrm{~K} 40$ & 34.5 & 32.3 & 30.1 & 25.2 & 35.4 & $31.5^{*}$ \\
\hline & N60K80 & 34.0 & 34.6 & 27.9 & 24.5 & 28.4 & 29.9 \\
\hline & N90K120 & $42.1 *$ & 36.7 & 29.4 & 35.9 & 30.0 & $34.8^{*}$ \\
\hline & $\mathrm{N} 120 \mathrm{~K} 160$ & $41.3^{*}$ & $50.6^{*}$ & 35.8 & $47.0^{*}$ & 35.2 & $41.9^{*}$ \\
\hline & Mean B & 34.4 & 37.2 & 28.6 & 30.0 & 30.4 & \\
\hline & \multicolumn{6}{|c|}{$\operatorname{LSD}_{05} \mathrm{~A}=8.0$} & \\
\hline
\end{tabular}




\begin{tabular}{|c|c|c|c|c|c|c|c|}
\hline \multirow[t]{14}{*}{ Apple tree } & \multicolumn{7}{|c|}{2018} \\
\hline & Control (no fertilizer) & 13.2 & 5.9 & 8.6 & 15.1 & 14.4 & 11.4 \\
\hline & N30K40 & 29.0 & 10.4 & 15.0 & 11.1 & 8.9 & 14.9 \\
\hline & N60K80 & 29.4 & 9.7 & 16.3 & 16.9 & 10.7 & 16.6 \\
\hline & N90K120 & $54.0^{*}$ & 20.9 & $78.5^{*}$ & 9.4 & 12.7 & $35.1^{*}$ \\
\hline & Mean B & 31.4 & 11.8 & 29.6 & 13.1 & 11.7 & \\
\hline & \multicolumn{4}{|c|}{$\mathrm{LSD}_{05} \mathrm{~A}=17.1$} & \multicolumn{3}{|c|}{$\mathrm{LSD}_{05} \mathrm{~A} \times \mathrm{B}=38.3$} \\
\hline & \multicolumn{7}{|c|}{2019} \\
\hline & Control (no fertilizer) & 12.9 & 30.5 & 32.2 & 15.0 & 26.5 & 23.4 \\
\hline & N30K40 & 13.8 & 33.8 & 35.6 & 16.9 & 32.5 & 26.5 \\
\hline & N60K80 & $54.5^{*}$ & $57.9^{*}$ & 44.3 & 18.1 & 45.6 & $44.2^{*}$ \\
\hline & N90K120 & 22.3 & 42.8 & $54.8^{*}$ & 23.6 & 39.4 & $36.7^{*}$ \\
\hline & Mean B & 26.1 & 41.2 & 41.7 & 18.4 & 36.0 & \\
\hline & $\mathrm{LSD}_{05}$ & $=10.5$ & $\mathrm{LSD}_{05} \mathrm{H}$ & $=11.7$ & $\mathrm{LSD}_{05} \mathrm{~A}$ & 23.4 & \\
\hline
\end{tabular}

* differences with control are reliable at 5\% significance level

The growth and fruits' ripening of cv. 'Ven'yaminovskoe' in the Central chernozem zone of the Russia continue until the end of August. In August 2019, the average $\mathrm{N}_{\text {min }}$ level in the soil of the apple orchard was significantly lower than in June and July (Table 3). In 2018, a similar effect was observed only in the soil of the plots with the highest dose of fertilizers (N90K120). In other experimental treatments in 2018, the dynamics of $\mathrm{N}_{\text {min }}$ correlated with the dynamics of precipitation - the lowest values of the indicator were in June during a prolonged drought.

For an apple tree, it has been shown that nitrogen distribution to support the growth of individual fruits and shoots is directly related to the distribution of assimilates in the plant [5]; therefore, one should expect differences in nitrogen uptake by trees in years with unequal fruit load. In our experiment, apple productivity in 2018 was 4.5 times higher than in 2019. Thus, the low $\mathrm{N}_{\min }$ level in the soil of unfertilized plots observed during the five months of 2018 was due not only to unfavorable hydrothermal conditions, but also to a higher nitrogen uptake by apple trees in the high-yielding year.

According to the gradation of soils by the content of mineral nitrogen suggested for fruit crops [17], the content of $\mathrm{N}_{\min }$ over $30 \mathrm{mg} / \mathrm{kg}$ is considered high, and $20 \ldots 30 \mathrm{mg} / \mathrm{kg}$ is medium. In the dry summer of 2018 , the $\mathrm{N}_{\min }$ level in the unfertilized soil of the experimental orchards was predominantly low - it varied within $13.4 \pm 8.3 \mathrm{mg} / \mathrm{kg}$. Only in May 2018, the content of $\mathrm{N}_{\min }$ in the soil of the cherry orchard approached a high level and reached $29.9 \mathrm{mg} / \mathrm{kg}$. In a more favorable 2019, the nitrogen content in both orchards was predominantly at a high level only due to the natural microbial activity of the studied soil (Table 3).

The application of nitrogen fertilizers contributed to an increase in the $\mathrm{N}_{\min }$ content by 1.5 ... 5 times depending on the nitrogen dose, the time of soil sampling and the hydrothermal conditions of the growing season (Table 3). At the same time, the dynamics of $\mathrm{N}_{\min }$ in the soil of fertilized and unfertilized plots was similar. In 2018 the content of $\mathrm{N}_{\text {min }}$ in the soil of both orchards reached extremely high values in the period from May to July with the application of nitrogen fertilizers in doses of $90 \ldots 120 \mathrm{~kg} / \mathrm{ha}$.

The fractional composition of mineral nitrogen compounds in the soil of the experimental plots was slightly different. Nitrates accounted for no more than $30 \%$ of the total amount of $\mathrm{N}_{\min }$, regardless of the form of fertilizer used, although urea contains nitrogen in the amide form, and in ammonium nitrate the ratio of $\mathrm{N}-\mathrm{NO}_{3}: \mathrm{N}^{-\mathrm{NH}_{4}}$ is $1: 1$.

The complexity of the nitrogen's biogeochemical transformation in ecosystems and the complexity of nitrogen metabolism processes in perennial woody plants make it necessary to combine soil and leaf diagnostics for an objective assessment of nitrogen nutrition of fruit crops and its successful correction by agrotechnical methods. The range of optimal 
nitrogen concentrations in apple leaves was $1.9 \ldots 3.0 \% \mathrm{DW}[7,18]$, in cherry leaves - 2.4 ... $3.4 \% \mathrm{DW}[18,19]$. During the two years of the experiment, the trees was not lacking of nitrogen regardless of the nitrogen fertilizers use (Table 4).

Table 4. Leaf nitrogen content of sour cherry trees cv. 'Turgenevka' and apple trees cv. 'Ven'yaminovskoe', 2018-2019, \% DW

\begin{tabular}{|l|c|c|c|c|}
\hline \multirow{2}{*}{ Treatments } & \multicolumn{2}{|c|}{ Sour cherry cv. 'Turgenevka' } & \multicolumn{2}{c|}{ Apple tree cv. 'Ven'yaminovskoe' } \\
\cline { 2 - 5 } & 2018 & 2019 & 2018 & 2019 \\
\hline Control (no fertilizer) & 2.44 & 2.54 & 2.41 & 3.17 \\
\hline N30K40 & 2.67 & 2.79 & 2.44 & 2.99 \\
\hline N60K80 & $2.82^{*}$ & $3.11^{*}$ & 2.57 & 2.92 \\
\hline N90K120 & $2.87^{*}$ & 2.98 & 2.26 & 3.29 \\
\hline N120K160 & $3.20^{*}$ & 3.01 & - & - \\
\hline LSD 0.05 & 0.36 & 0.51 & 0.20 & NS \\
\hline
\end{tabular}

$*$ differences with control are reliable at $5 \%$ significance level

In average, for all variants of the experiment, nitrogen content in sour cherry leaves was the same in 2018 and 2019, despite the differences in soil nitrogen regime observed in these years. However, in 2018, with sharp seasonal fluctuations in the content of $\mathrm{N}_{\min }$ in the soil, the fertilization with nitrogen in doses of $60 \ldots 120 \mathrm{~kg} /$ ha led to a significant increase in the nitrogen status of the leaves. With a more stable nitrogen regime in 2019, this effect was observed only in the variant with the fertilization of $60 \mathrm{~kg} / \mathrm{ha}$ of nitrogen (Table 4).

Unlike cherry, the nitrogen status of apple leaves did not depend on the use of nitrogen fertilizers, but it was significantly lower in 2018 under contrasting weather conditions and high fruit load.

\section{Conclusion}

The study of the soil nitrogen regime at fruit tree plantations showed that the most important factors influencing the dynamics of $\mathrm{N}_{\min }$ were meteorological conditions, productivity of trees, and peculiarities of nitrogen uptake by the studied crops. During the two growing seasons, the lowest level of the indicator in the soil under cherry trees was in July during fruit ripening, while in the soil of the apple orchard, a low nitrogen content was noted in August.

Application of nitrogen fertilizers to the soil of sour cherry and apple orchards in doses of $30 \ldots 120 \mathrm{~kg} / \mathrm{ha}$ contributed to an increase in the content of $\mathrm{N}_{\min }$ by $1.5 \ldots 5$ times, depending on the dose of nitrogen. At the same time, the dynamics of $\mathrm{N}_{\min }$ in the soil of fertilized and unfertilized plots was similar.

Loamy haplic Luvisols in the climatic conditions of the Central Russian Uplands can provide a favorable level of nitrogen nutrition for apple and sour cherry trees in the first years of tree fruiting with no additional nitrogen fertilizers' application only due to natural microbiological activity. This is confirmed by the high concentrations of nitrogen in the leaves $(2.83 \pm 0.15$ and $2.76 \pm 0.27 \%$ DW for cherry and apple trees, respectively) and the absence of a significant positive effect of fertilizers on the productivity of trees.

\section{References}

1. M.M.Umarov, A.V. Kurakov and A.L. Stepanov, Microbial transformation of nitrogen in soil, 138 (2007)

2. V.G.Mineev, Agricultural Chemistry, 720 (2004) 
3. C. Carranca, G.Brunetto and M.Tagliavini, Plants 7(1), $4 \quad$ (2018) https://doi.org/10.3390/plants7010004

4. D. Neilsen, P. Millard, G. H. Neilsen and E. J. Journal of the American Society for Horticultural Science 126(1), 144-150 (2001) DOI: https://doi.org/10.21273/JASHS.126.1.144

5. LiXin Zhang, MingYu Han, CaiPing Zhao, ChangHong Liu, FangFang Zhang, LinSen Zhang \& BingZhi Li, Journal of Plant Nutrition 35(10), 1557-1571 (2012) DOI: 10.1080/01904167.2012.689914G.M.

6. A.K. Kondakov, Fertilizing Fruit Trees, Berry-Fields, Nurseries and Flower Crops, 327 (2007)

7. $\mathrm{Yu}$. V.Trunov, Biological principles of mineral apple nutrition, 428 (2013)

8. V.G.Mineev, V.G.Sychev, O.A.Amelyanchik, T.N.Bolsheva, N.F.Gomonova, E.P.Durynina, V.S.Egorov, E.V.Egorova, N.L. Edemskaya, E.A.Karpova, et al. Educational Aid on Agricultural Chemistry, 2nd ed., 689 (2001)

9. Program and methodology of variety study of fruit, berry and nut crops, 608 (1999)

10. B.A. Dospekhov, A Field Experiment Method, 351 (1985)

11. A.I. Kuzin, Yu.V. Trunov and A.V. Soloviev, Agricultural biology 53(50), 1013-1024 (2018) DOI: 10.15389/agrobiology.2018.5.1013rus

12. E.V. Leonicheva, T.A. Roeva, L.I. Leontieva and M.E. Stolyarov, Bulletin of KrasGAU 11(164), 87-97 (2020) DOI: 10.36718/1819-4036-2020-11-87-97

13. T.A. Roeva, E.V. Leonicheva, L.I. Leontieva and M.E. Stolyarov, Pomiculture \& Small Fruits Culture in Russia 58, 341-349 (2019) DOI: 10.31676/2073-4948-2019-58341-349

14. T.A. Roeva, E.V. Leonicheva, L.I. Leontieva and M. E. Stolyarov, Hort, Vitic. 3, 3743 (2020) DOI: 10.31676/0235-2591-2020-3-37-43

15. P.R. Ernani, D.A. Rogeri, M.M. Proença, and J. Dias, Revista Brasileira de Fruticultura 30(4), 1113-1118 (2008) DOI:https://doi.org/10.1590/S0100-29452008000400044

16. A. Sadowski, E.Jadczuk, Acta Horticulturae 564, 279-284 (2001) DOI: 10.17660/ActaHortic.2001.564.32

17. V.P. Popova, N.N. Sergeyeva, T.G. Fomenko and N.G. Pestova, Scientific publications of FSBSO NCRRIH\&V 9, 122-130 (2016)

18. C. Stiles Warren, Reid W. Shaw, Cornell Cooperative Extension Information Bulletin 219, 23 (1991)

19. Semenuk G.M., Diagnostics of mineral nutrition of stone fruit crops with the use of information retrieval systems, 323 (1983) 